\title{
Dangerous liaisons disperse the Mediterranean dwarf palm: fleshy-pulp defensive role against seed predators
}

\author{
José M. Fedriani ${ }^{1}$ and Miguel Delibes \\ Estación Biológica de Doñana, Consejo Superior de Investigaciones Científicas, Avda. Américo Vespucio s/n, \\ Isla de la Cartuja 41092 Sevilla, Spain
}

\begin{abstract}
We chose the interaction between the Mediterranean dwarf palm (Chamaerops humilis) and its major seed disperser, the Eurasian badger (Meles meles), to evaluate the hypothesis that endozoochory is characterized by a mixture of conflicting and overlapping interests, with the capacity of being positive or negative for plant fitness. For instance, because of the potential protective role against invertebrate seed predators of $C$. humilis pulp, we expected that badger-ingested diaspores (i.e., seeds without pulp) would show lower survival than control seeds with the pulp attached. Conversely, due to the possible germination inhibitory function of $C$. humilis fruit pulp, it was also likely that badger-ingested seeds germinate in higher proportion than control seeds. We evaluated our predictions by carrying out a field sowing and monitoring it over two years. We estimated several stage-specific transition probabilities as well as the cumulative probability of seedling recruitment under different treatments. Our experimental results revealed the multifunctionality of $C$. humilis fruit pulp and that fruit ingestion by badgers had conflicting outcomes for the palm. As predicted, seed survival was much lower and seed predation by invertebrates much higher for badger-ingested than for control seeds, suggesting a defensive role of $C$. humilis ripe fruit pulp. All early-emerged seedlings came from badger-ingested seeds, suggesting an inhibitory function of fruit pulp. Though we did not find an effect of removal from the maternal environment on most components of fitness, seedling survival for badger-ingested seeds was higher away from than beneath conspecifics. Badgers imposed a sizeable short-term fitness cost to $C$. humilis and therefore could be categorized as a "dangerous liaison." Nonetheless, because of the high mobility of the badger, its dispersal service appears paramount given the severe fragmentation and isolation of most $C$. humilis populations across the highly humanized Mediterranean basin. Our study thus illustrates the necessity of assessing concurrently direct and indirect effects of plant-disperser interactions at different stages of the plant life cycle and recruitment process.
\end{abstract}

Key words: Chamaerops humilis; dangerous liaisons; Doñana National Park, Guadalquivir River, Spain; fleshy pulp; fragmentation; indirect negative effects; Meles meles; recruitment; seed dispersal costs; seed predation; transition probabilities.

\section{INTRODUCTION}

Despite the fact that ecological interactions are often described as either antagonistic or mutualistic, most of them correspond to a mixture of conflicting and overlapping interests, with the capacity of being positive or negative for the participants (Bronstein 2001, van Baalen and Jansen 2001, Bronstein et al. 2006). In some instances, positive or negative aspects clearly predominate (e.g., predator-prey interactions; see Barbosa and Castellanos 2005 review), but in many cases the balance may be subtler (e.g., many plant-animal interactions; Herrera and Pellmyr 2002, Gómez and Zamora 2005, J. N. Thompson 2005, Herrera 2009). Where there is a benefit associated with an interspecific interaction, but a

Manuscript received 24 November 2009; revised 15 July 2010; accepted 6 August 2010. Corresponding Editor: L. S. Adler.

${ }^{1}$ E-mail: fedriani@ebd.csic.es substantial risk as well, the interaction has been labeled a "dangerous liaison" (van Baalen and Jansen 2001, Ellstrand 2003, Barillas-Mury and Kumar 2005).

Investigations on "endozoochory" (i.e., seed dispersal in animal interiors) often have highlighted plant fitness benefits, even though such dispersal modality also entails substantial risks for the plant and, thus, its overall outcome can be difficult to predict (Bronstein et al. 2007). For instance, paired seed-disperser mutualisms are embedded within a network of interactions in which negative indirect effects (sensu Strauss and Irwin 2004) are likely, although seldom accounted for. In tropical endozoochores, pulp removal by frugivorous vertebrates appears to improve fruit availability or quality for subsequent consumers (e.g., invertebrate seed predators) having thus a significant fitness cost for these plants (Silvius and Fragoso 2002, Fragoso et al. 2003, Filardi and Tewksbury 2005). Nevertheless, fruit consumption by vertebrates also can enhance seed germinability and recruitment (Traveset et al. 2007). 
Thus, trade-offs as a result of plant-frugivore interactions are predictable. Surprisingly, however, we know very little about the net outcome of potentially conflicting direct and indirect effects of plant-frugivore interactions. For example, are indirect costs of endozoochory (e.g., augmented seed predation) overridden by the direct benefits, such as enhanced germination?

Seed dispersal also entails leaving the maternal environment, which often confers fitness advantages at the propagule level, such as escaping from a place with high risk of predation or infection by microbial pathogens, avoidance of chemical allelopathy and mechanical inhibition, etc. (Fenner and Thompson 2005). Nonetheless, the assessment of the fitness outcomes of leaving the maternal environment and arriving in a contrasting microhabitat can vary, for example, with the fitness component accounted for (seed survival, seedling establishment; Rey and Alcántara 2000, Balcomb and Chapman 2003, Traveset et al. 2003). Because direct and indirect effects of endozoochory can be contradictory, context-dependent (Schupp 2007), and also dependent upon the level of observation (e.g., individual vs. population; Spiegel and Nathan 2007, Schupp et al. 2010), their net outcome in terms of plant demography and fitness is difficult to forecast. In spite of their importance, integrative analyses accounting for direct and indirect effects of endozoochory along different stages of the plant life cycle and recruitment process are virtually lacking (but see Balcomb and Chapman 2003). Consequently, our knowledge concerning the factors governing the dynamic of many vertebrate-dispersed plant populations could be incomplete.

To our knowledge, this paper describes the first experimental investigation designed precisely to evaluate concurrently the direct and indirect benefits and costs of endozoochory along different stages of a plant recruitment process. In so doing, we chose the interaction between the Mediterranean dwarf palm Chamaerops humilis and its major seed disperser, the Eurasian badger Meles meles, in an area where most likely alternative dispersers have gone extinct. The ripe pulp of many fruits holds multiple adaptive functions, including attraction of seed dispersers, inhibition of seed germination, alteration of seed gut passage time, and defense against seed predators and pathogens (Cipollini and Levey 1997, Cipollini 2000); therefore, we hypothesized that pulp consumption by badgers would have several, potentially conflicting, outcomes for $C$. humilis fitness. To evaluate our hypotheses linking seed ingestion and dispersal to recruitment, we used a simple model of a plant life cycle, starting from mature seeds and composed of life stages connected by transition probabilities that are determined by a number of processes (Rey and Alcántara 2000, Balcomb and Chapman 2003, Traveset et al. 2003). Under this framework, we made the following predictions. (1) Because palm seeds typically have a nutritious endosperm that attracts pathogens and invertebrate seed predators (e.g., bruchid beetles; Silvius and Fragoso 2002, Fragoso et al. 2003) and because of the potential protective role of $C$. humilis pulp (see Anstett 1999), we expected that badgeringested diaspores (i.e., seeds without pulp) would show lower survival than control diaspores (i.e., seeds with the pulp attached). (2) Because of the possible germination inhibitory function of $C$. humilis fruit pulp and/or because of seed scarification during gut passage, we predicted that, for the subset of seeds that survived, badger-ingested seeds would germinate in higher proportion and faster than control seeds (Traveset et al. 2007). (3) Due to their presumed early emergence, seedlings from badger-ingested seeds would survive longer than those emerged from control seeds (Verdú and Traveset 2005). (4) Because pathogens and seed/ seedling predators tend to be more abundant beneath reproductive plants, we expected lower seed and seedling survival beneath than away from fruiting palms (Janzen 1970). We evaluated these predictions by carrying out an experimental sowing resembling the natural presentation of $C$. humilis seed in the field, whose ultimate purpose was to answer our main research questions: Are there conflicting positive and negative effects in the interaction between $C$. humilis and badger, and what is the net outcome for plant fitness?

\section{Methods \\ Study area}

The study was carried out from November 2005 to February 2008 in the Doñana National Park $\left(510 \mathrm{~km}^{2}\right.$; $37^{\circ} 9^{\prime} \mathrm{N}, 6^{\circ} 26^{\prime} \mathrm{W}$; elevation $0-80 \mathrm{~m}$ ), located on the west bank of the Guadalquivir River in southwestern Spain. The Doñana area is a humanized and fragmented landscape, in which suitable habitat patches (Mediterranean scrubland, pine forest) are isolated from one another by cultivated fields, towns, marshes, or sand dunes (Fedriani et al. 2010). Our focal C. humilis population occurs within one of those scrubland patches $\left(\sim 3 \mathrm{~km}^{2}\right)$, dominated by Pistacia lenticus, Halimium halimifolium, Ulex spp., Cistus spp., and Myrtus communis shrubs, growing singly or in small clumps separated by open spaces with some forbs and grasses (Fedriani and Delibes 2009a). Scattered across the area there are Quercus suber, Pyrus bourgaeana, Olea europaea var. sylvestris, Fraxinus angustifolia, and Pinus pinea trees. The climate is mediterranean subhumid, characterized by dry, hot summers (June-September) and mild, wet winters (November-February). Annual rainfall varies widely, ranging during 1984-2005 between 170 and $1028 \mathrm{~mm}(540 \pm 63 \mathrm{~mm}$, mean $\pm 1 \mathrm{SE})$, with most rain falling during the winter $(310.7 \pm 51.4 \mathrm{~mm})$ and extreme drought occurring during the summer (34.1 $\pm 7.9 \mathrm{~mm}$ ).

\section{Study species}

Chamaerops humilis L. (Arecaceae; see Plate 1) is an endemic dwarf palm (usually $\sim 1.5 \mathrm{~m}$ high) of the 
western Mediterranean basin, representative of the PrePliocene paleo-tropical ancestral lineages in the area (J. D. Thompson 2005). In Doñana, this dioecious palm is relatively abundant in patches of scrubland and open pine $(P$. pinea) forest. It flowers during spring (MarchMay; Herrera 1989) and the fruits ripen in autumn (September-November). The fruits are "polydrupes," comprising one to three drupes; however, we hereafter will use the term fruit to refer to the drupe, which behaves as an independent dispersal unit (Herrera 1989). Unripe fruits are bright green, turning to dull yellow to brown when ripe (see Appendix). The seed (usually 0.6$0.8 \mathrm{~g})$ comprises a small cylindrical embryo $(\sim 2 \mathrm{mg})$, which is surrounded by several layers, from inner to outer: (1) a nutritious endosperm, (2) a wide woody layer or endocarp, (3) a fleshy and fibrous mesocarp (the pulp, that smells strongly of rancid butter when ripe), and (4) the thin outer layer or exocarp (González-Benito et al. 2006, Hasnaoui et al. 2009). Fruits are attached to infructescences (or ramets) of up to $30 \mathrm{~cm}$ long (20-40 fruits per ramet; J. M. Fedriani and M. Delibes, unpublished data) and located at $\sim 10-30 \mathrm{~cm}$ from the ground level. Germination in C. humilis is hypogeal and remote, with most seedlings emerging during the spring. In our study area, seedlings are frequently observed emerging from both fresh and old ( $>1$ year) badger feces (J. M. Fedriani and M. Delibes, unpublished data; Appendix). This is consistent with results from controlled assays revealing that $C$. humilis seeds keep their germination capacity for $\sim 1.5$ years (González-Benito et al. 2006). Chamerops humilis has a well-known ability to thrive on poor nutrient soils (Herrera 1989, Simón et al. 2010) and most seedling mortality is due to desiccation during summer droughts (J. M. Fedriani and M. Delibes, unpublished data).

The Eurasian badger (Meles meles) is a mustelid mammalian carnivore with generalist feeding habits. In Doñana, badgers weigh up to $10 \mathrm{~kg}$, move over home ranges of several hundred hectares, and are highly mobile and capable of straight-line movements of several kilometers (Fedriani et al. 1999, Revilla and Palomares 2002). Badgers are known to be important local seed dispersers for several fleshy-fruited shrubs (Fedriani and Delibes 2009a, b, Fedriani et al. 2010). When feeding on $C$. humilis, badgers ingest large numbers of ripe fruits. The pulp is digested in the badger's gut, and endocarps are defecated virtually with no fecal material other than seeds (see Appendix). In our study site and elsewhere (Kruuk 1989), badgers defecate in latrines, and aggregations of endocarps are created within the Mediterranean shrubland, where there is a high density of $C$. humilis ( $>400$ palms/ha; J. M. Fedriani and M. Delibes, unpublished data). Badgers also deliver $C$. humilis seeds in vacant habitats, such as "dehesas" (Fedriani et al. 1999, 2010) with a relative low palm density ( $\sim 40$ palms/ha). Density of palm saplings (one, two, and three years old) is high in sites used as latrines by badgers (J. M. Fedriani and M. Delibes, unpublished data; Appendix).

Rabbits (Oryctolagus cuniculus), red deer (Cervus elaphus), and rodents frequently depredate on immature fruits (Herrera 1989; J. M. Fedriani and M. Delibes, unpublished data). Rabbits also feed on ripe fruit but they only eat the fleshy mesocarp, leaving the endocarp intact either still attached to ramets or detached and beneath mother plants (J. M. Fedriani and M. Delibes, unpublished data; Appendix). Due to the low abundance of red foxes (Vulpes vulpes) during our study (Fedriani and Delibes 2009b), they rarely dispersed palm seeds. Whereas seeds depredated by invertebrates (e.g., bruchid beetles) are regularly found beneath reproductive palms, seed predation by rodents is relatively infrequent (J. M. Fedriani and M. Delibes, unpublished data); thus, invertebrates appear to be the major predators of mature $C$. humilis seeds.

\section{Experimental field seed sowing}

Because we aimed to assess the effect of badgers on $C$. humilis seedling recruitment and because in our study system pulp removal and seed scarification were inexorably coupled, we evaluated the overall effect of "fruit ingestion" (i.e., pulp removal plus seed scarification) on seed fate by comparing control (i.e., noningested, with ripe pulp attached) and badger-ingested seeds under field conditions. Our procedure thus differed somewhat from that used in studies focused on identifying the function of fleshy pulp (which often use hand-depulped fruits) rather than to quantify the effects of seed ingestion along the plant recruitment process (Silvius and Fragoso 2002, Filardi and Tewksbury 2005; but see Fragoso et al. 2003). To attain control fruits, in November 2005 the crop from 20 fruiting individuals well distributed throughout the study site were collected. Control fruits (i.e., whole, ripe fruits with pulp) were visually examined and those with invertebrate eggs, tracks of larvae/adult beetles through the pulp, aborted, or with shrivelled aspect were discarded. Selected fruits $(n=300)$ were stored for a few days in paper bags in the dark at room temperature. Badger-ingested seeds (i.e., endocarps without pulp) were picked from fresh badger feces collected in the field (Traveset et al. 2001b, Fragoso et al. 2003, Nogales et al. 2005) during the same time period and near the fruiting plants from which control seeds were attained. Badger feces were easily discriminated because they are deposited in small holes often buried shallowly with loose substrate and, typically, with a distinctive musky smell and associated badger footprints (Fedriani et al. 1999, 2010). As with control seeds, badger-ingested seeds were visually examined to ensure that only healthy noninfected seeds were used in our sowing. Then, selected badger-ingested seeds $(n=$ 300) were stored for a few days in the dark at room temperature until sowing.

To evaluate the combined effect of badger ingestion (i.e., "ingestion") and the removal from fruiting palms 
(i.e., "removal") on $C$. humilis seed and seedling fate, we haphazardly chose 15 fruiting individuals (or random blocks), with $\sim 15$-m spacing between adjacent blocks. We used a $2 \times 2$ experimental design whose factors were "ingestion" (badger-ingested and control seeds) and "removal" (beneath and away [5-10 $\mathrm{m}$ in open microhabitat] from any reproductive palm; e.g., Fedriani and Delibes 2009a). We focus on those two removal levels because large quantities of nondispersed seeds accumulate each season beneath fruiting $C$. humilis (J. M. Fedriani and M. Delibes, unpublished data). Further, open interspaces among shrubs received almost one-third of badger feces in the area (Fedriani and Delibes 2009b), which are most often delivered within 10 $\mathrm{m}$ from $C$. humilis neighborhoods (J. M. Fedriani and M. Delibes, unpublished data), although likely further away from their specific mother palms. In each random block, we set the following four treatment combinations: (1) badger-ingested seeds beneath a fruiting $C$. humilis, (2) control seeds beneath a fruiting $C$. humilis, (3) badger-ingested seeds away from any conspecific, and (4) control seeds away from any conspecific. In each experimental block, we placed two seed depots for badger-ingested and two seed depots for control seeds (overall, four seed depots). Each seed depot consisted of an open-bottomed plastic beaker $(7 \mathrm{~cm}$ diameter) pushed partly into the ground (Robertson et al. 2006, Fedriani and Delibes 2009a). Five seeds of one treatment were sown in each depot and buried $(\sim 0.5$ $\mathrm{cm}$ depth) with in situ soil, which previously had been sieved to remove nonexperimental seeds. Because the pulp of $C$. humilis fruits is digested in the badger's gut and usually endocarps are defecated with virtually no other fecal material (see Appendix), we sowed experimental seeds without additional fecal material. However, badgers in Doñana (and elsewhere; see Kruuk 1989) most often deposit their feces in small holes and bury them shallowly with loose substrate, which could certainly prevent seed detection and attacks by invertebrates. Therefore, to resemble the natural presentation of badger-dispersed seeds, sowed badger-ingested seeds were not embedded in additional fecal material and were buried shallowly with the local sandy substrate. On the other hand, during the dispersal season, heavy winter rains shallowly bury most fallen ripe fruits. Accordingly, control seeds (i.e., whole, ripe fruits with pulp) were buried $(\sim 0.5 \mathrm{~cm}$ depth) within sandy substrate to resemble their natural presentation (e.g., Fedriani and Delibes 2009a).

To evaluate potential contamination by nonexperimental seeds, we placed in each block two extra depots, following the above procedure except with no sown seeds. To avoid trampling by ungulates and rodent seed predation, we covered all seed depots with $1-\mathrm{cm}$ mesh cages $(28 \times 18 \times 13 \mathrm{~cm})$. The mesh size of the cages did not exclude fungi, bacteria, and small insects, which, in our study and elsewhere (Cipollini and Levey 1997, Cazetta et al. 2008), are the most important predators of mature seeds. To monitor seedling emergence and survival, we checked the sowings monthly from January 2006 to February 2008. Ball-headed needles of variable colors were placed next to each emerged seedling upon each check, allowing us to distinguish between monthly seedling cohorts (Fedriani and Delibes 2009a; Appendix). Most seedling mortality was due to desiccation during the first summer after emergence; thus seedling survival up to the end of this study (26 months after seed sowing) was considered a fair proxy of establishment.

\section{Seed survival, bruchid predation, and seed rotting}

Many circumstances may explain failures in germination, seed predation by beetles being one of the most pervasive. At the end of our study in February 2008, we estimated seed fate by retrieving all remaining endocarps from 12 out of 15 experimental blocks. Three blocks were not checked due to logistic reasons. We were able to retrieve most sown diaspores $(83.3 \% ; n=480)$, from which we visually assessed bruchid attack (e.g., Silvius and Fragoso 2002) and rotting due to fungus pathogens. Typically, an endocarp attacked by bruchids showed several holes, with the embryos and most endosperms consumed. Bruchid holes were located at either the distal, narrow tip of the endocarp or at the middle of endocarps (Appendix). Germination pores were generally located at the proximal base and clearly differed in size and contour from bruchid holes (Appendix). In addition, we submitted 54 non-germinated seeds that were not attacked by bruchids to viability tests. Before the test, seeds were immersed in distilled water for $24 \mathrm{~h}$ and then cut in half to expose the embryo. Seed viability was assessed by color changes of the embryos after being submerged in $1 \%$ tetrazolium blue $(2,3,5$-triphenyltetrazolium chloride) for $24 \mathrm{~h}$ at $30^{\circ} \mathrm{C}$ (Booth and Ghend 1993). To test the validity of our procedure, seven seeds recently collected from a fruiting $C$. humilis were also tested for viability following the same procedure. After $24 \mathrm{~h}$ in the chamber, the embryos of all seven seeds were clearly stained by tetrazolium blue, indicating they were all viable.

\section{Transition probabilities}

We calculated several transition probabilities (TP) and the cumulative probability of $C$. humilis recruitment (CPR) from seed sowing to seedling establishment on a per treatment basis. Transition probabilities were calculated as the ratio of the number of individuals completing a stage over the number of individuals entering that same stage (e.g., Rey and Alcántara 2000, Traveset et al. 2003, Vilà et al. 2006). Specifically, we calculated the following four transition probabilities: (1) seed survival, i.e., the number of seeds that survived (either germinated or not) at the end of the study divided by the total number of sown seeds; (2) seed germination, i.e., the number of seeds that germinated divided by the number of surviving seeds; (3) seedling emergence, i.e., the number of seedlings emerged divided by the number 
of seeds that germinated; and (4) seedling survival, i.e., the number of seedlings that survived at the end of the study divided by the number of emerged seedlings. We then calculated the cumulative probability of recruitment as the product of those four stage-specific transition probabilities (Fig. 2). Interpretation of TPs requires the consideration of some limitations of our sampling procedure. To prevent interferences of the germination and emergence processes, seed fate was assessed at the conclusion of the study and thus we missed the chronological order of some events (e.g., seed predation events could have occurred before and/or after germination was initiated). However, whatever the chronological order, it did not alter our estimates of transition probabilities nor the cumulative probability of recruitment. Also, because only eight seedlings emerged before the summer of 2006, the probability of seedling survival was calculated for a pooled sample of seedlings regardless of their emergence date. Finally, badgers in Doñana deliver feces in a myriad of microsites (open interspaces and at least up to 10 shrub species; Fedriani and Delibes 2009b); thus, it was not feasible to account for all possible microsites in our field experiment. Hence, we focused on two highly relevant microsites and applied a totally crossed factorial design, ensuring that experimental units (i.e., depots of sown seeds) yielded comparable measurements of seed and seedling fate and allowed for rigorous comparisons of TPs and CPRs under different treatment combinations.

\section{Statistical analyses}

Analyses on seed survival, bruchid predation, and germination were based on available data from the 12 experimental blocks that were checked at the end of our study. In analyzing seedling survival, however, we accounted for available data from all 15 experimental blocks. Most data were analyzed fitting generalized linear mixed models using the SAS macro GLIMMIX (SAS Institute2005), including ingestion, removal, and their second-order interaction as fixed effects. Experimental block was included as a random factor. Because of the binomial nature of the response variables (e.g., the number of survived seedlings divided by the number of emerged seedlings), we used binomial error and logit link functions. Adjusted means and standard errors were calculated using the LSMEANS statement and backtransformed using the appropriate Taylor's series approach. When the interaction between any two factors was significant, we performed tests for the effect of a given factor at the different levels of the other factor ("tests of simple main effects"), using the SLICE option in the LSMEANS statement of the MIXED procedure (SAS Institute 2005). Generalized linear models do not make allowances for censored data and some experimental seeds could have germinated after the 26-month monitoring period; however, this possibility is unlikely to have affected our results since only a small number of sown seeds were viable at the end of our study (see Results).

To evaluate the potential effects of ingestion and removal on the speed of seedling emergence, we used failure time analyses and fitted Cox proportional hazard regression models to data consisting of the number of months between sowing and seedling emergence (e.g., Santamaría et al. 2002, Rodríguez et al. 2005). Block was included in the model as a "frailty" (i.e., random) term, and the significance of each factor and interaction was evaluated by backwards stepwise elimination from the full model (Therneau and Grambsch 2000). In comparing successive models, we calculated the double absolute difference of their respective expectation maximization (EM) likelihood algorithms and compared that value against a chi-square with $k-1$ degrees of freedom, $k$ being the number of levels (or combination of levels) of the factor (or interaction) being tested. For the frailty factor we also assumed a chi-square distribution with one degree of freedom (Therneau and Grambsch 2000).

\section{REsults}

Extra depots set without $C$. humilis seeds showed that contamination by nonexperimental seeds was nil. Further, tetrazolium tests indicated that only the embryos of seven seeds (of 54 apparently sound seeds) were viable 26 months after sowing. These results indicated that our experimental procedure and the time window encompassed by the study were appropriate to accurately evaluate seed and seedling fate.

\section{Seed survival, bruchid predation, and seed rotting}

Our generalized linear model indicated that, as predicted, seed survival was significantly lower for badger-ingested seeds than for control seeds $(P<0.01$; Fig. 1B, Table 1). Unexpectedly, however, removal did not have a significant effect on seed survival (Table 1). The lack of significant interaction between ingestion and removal $(P=0.275)$ indicated that the effect of ingestion on seed survival was similar beneath and away from fruiting conspecifics (Fig. 1B). While checking the sowings, bruchid beetles were observed in several instances emerging from unburied $C$. humilis seeds. The overall rate of invertebrate seed predation was high ( $\sim 21.0 \%$; Fig. 1A). In concordance with seed survival results, there was a significant ingestion effect (Table 1), with the mean percentage of seed predation for badgeringested over threefold higher than that for control seeds $(31.0 \% \pm 13.1 \%$ and $9.9 \% \pm 14.1 \%$ [mean $\pm \mathrm{SE}$ ], respectively; Fig. 1A). Neither removal as main effect nor its interaction with ingestion had an effect on seed predation (Table 1). Thus, pulp handling by badgers seemed to increase seed predation by bruchid beetles, and this pattern was not affected by the removal from fruiting conspecifics, at least at the spatial scale tested.

Overall, 35 C. humilis seeds were found with either clear external signs of rotting or were rotten when cut 

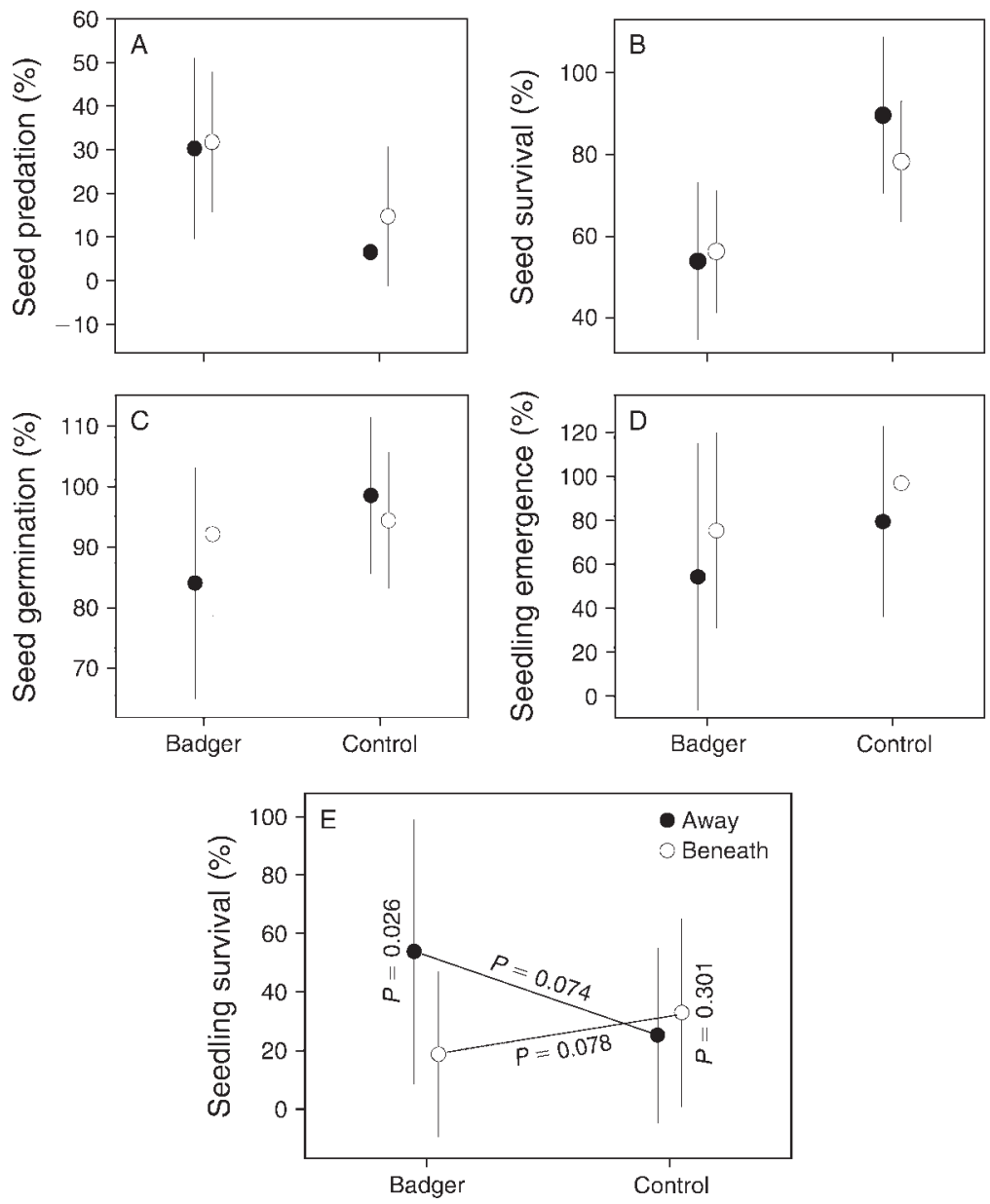

FIG. 1. Corrected percentages (mean $\pm \mathrm{SE}$ ) of $(\mathrm{A})$ invertebrate seed predation, (B) seed survival, and $(\mathrm{C})$ germination of control seeds of the Mediterranean dwarf palm (Chamaerops humilis) and C. humilis seeds ingested by the Eurasian badger (Meles meles) both beneath (open circles) and away from (black circles) reproductive conspecifics and (D) seedling emergence and (E) survival under the same factorial design. Because for seedling survival there was a significant interaction effect between "Ingestion" and "Removal," we report the $P$ values for the four simple main effects involved in the interaction. The study was carried out from November 2005 to February 2008 in the Doñana National Park, located on the west bank of the Guadalquivir River in southwestern Spain.

open. The percentage of non-predated or germinated seeds that had rotted at the conclusion of the study was slightly, but not significantly, higher for badger-ingested $(55.3 \% \pm 19.2 \%)$ than for control seeds $(36.4 \% \pm 26.7 \%$; $P=0.276)$. Similarly, the percentage of rotten seeds beneath and away from conspecifics were not different $(44.2 \% \pm 20.8 \%$ vs. $47.1 \% \pm 26.5 \%$, respectively; $P=$ $0.856)$, and the interaction between removal and ingestion was not significant $(P=0.552)$. These results corroborate the idea that invertebrates rather than

TABLE 1. Main results of our generalized linear mixed models testing the effects of fruit ingestion by badgers (Meles meles) (I; badger-ingested vs. control seeds) and badger seed removal from fruiting palms (R; beneath vs. away from any reproductive palm) on seed predation by invertebrates and seed and seedling demography of fruiting Mediterranean dwarf palms (Chamaerops humilis).

\begin{tabular}{|c|c|c|c|c|c|c|c|c|c|c|c|c|c|c|c|}
\hline \multirow[b]{2}{*}{ Factor } & \multicolumn{3}{|c|}{ Seed predation } & \multicolumn{3}{|c|}{ Seed survival } & \multicolumn{3}{|c|}{ Germination } & \multicolumn{3}{|c|}{ Emergence } & \multicolumn{3}{|c|}{ Seedling survival } \\
\hline & $\mathrm{df}$ & $F$ & $P$ & df & $F$ & $P$ & df & $F$ & $P$ & df & $F$ & $P$ & df & $F$ & $P$ \\
\hline Ingestion (I) & 1,26 & 6.51 & 0.017 & 1,26 & 12.10 & 0.002 & 1,26 & 4.99 & 0.034 & 1,26 & 1.49 & 0.232 & 1,247 & 0.36 & 0.551 \\
\hline Removal (R) & 1,26 & 0.79 & 0.384 & 1,26 & 0.79 & 0.381 & 1,26 & 0.19 & 0.668 & 1,26 & 1.12 & 0.299 & 1,247 & 2.35 & 0.126 \\
\hline $\mathrm{I} \times \mathrm{R}$ & 1,26 & 0.58 & 0.454 & 1,26 & 1.24 & 0.275 & 1,26 & 2.82 & 0.105 & 1,26 & 0.16 & 0.696 & 1,247 & 6.13 & 0.014 \\
\hline
\end{tabular}

Notes: Values in boldface are significant at $P<0.05$. The study was carried out from November 2005 to February 2008 in the Doñana National Park, located on the west bank of the Guadalquivir River in southwestern Spain. 


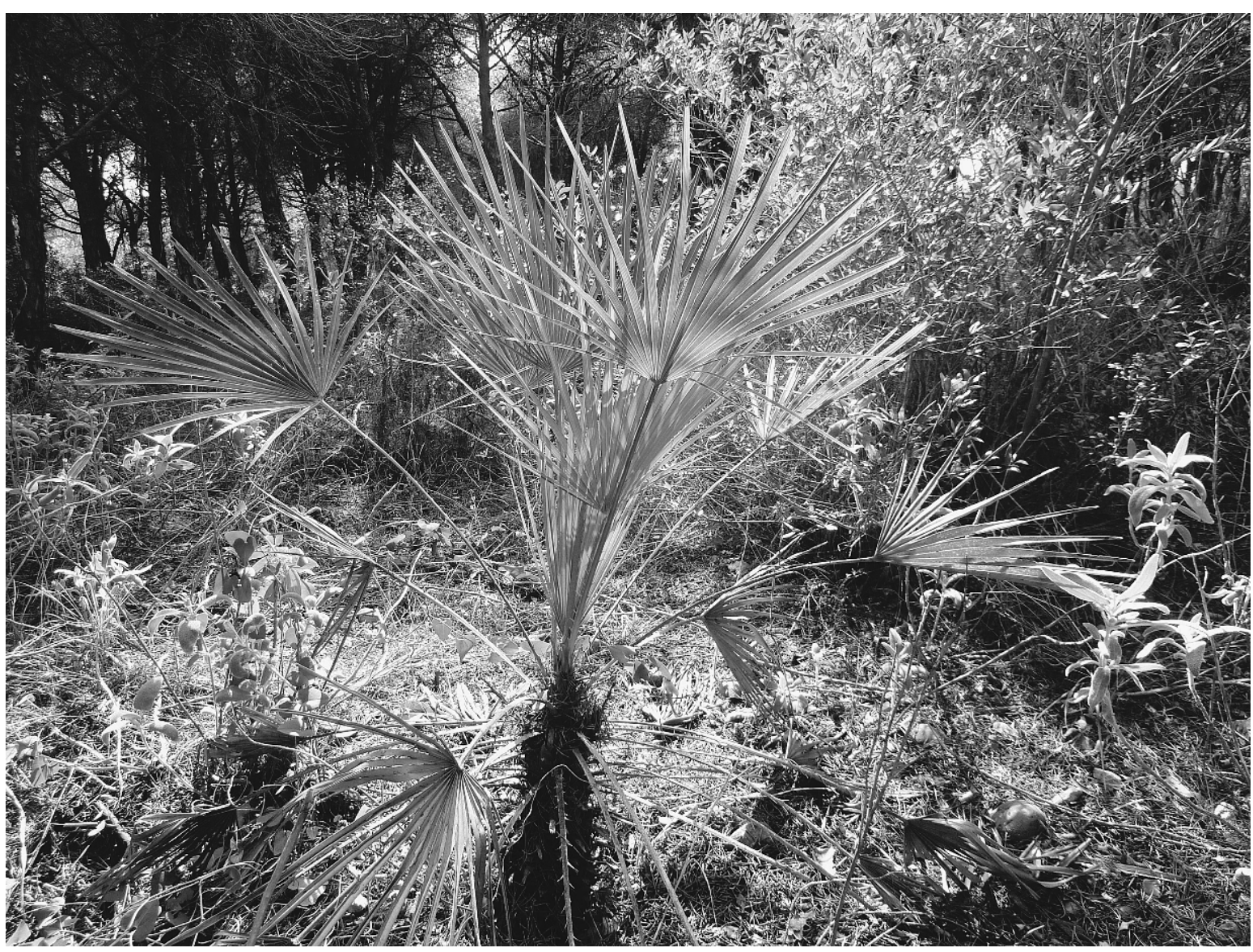

Plate 1. The Mediterranean dwarf palm Chamaerops humilis is a shrub-like bushy palm with one or several stems growing from the base and with fan-like leaves. Our study was carried out from November 2005 to February 2008 in the Doñana National Park, located on the west bank of the Guadalquivir River in southwestern Spain. Photo credit: M. Delibes.

microbial pathogens were the major agents causing the observed pattern of $C$. humilis seed survival.

\section{Seed germination and seedling emergence}

Most $C$. humilis seeds that were not predated or rotted had germinated by the end of the study $(92 \%, n=282)$. Our generalized linear model indicated that, once the block effect was controlled for, differences in germination were related to ingestion, with the percentage of germination of control seeds being significantly (Table 1) higher than that of badger-ingested seeds $(97.1 \% \pm$ $10.1 \%$ and $88.7 \% \pm 12.3 \%$, respectively; Fig. 1C). Neither removal as main effect nor its interaction with ingestion had an effect on seed germination (Table 1).

Seedling emergence was particularly variable within treatments (Fig. 1D), and thus, no differences were found for ingestion, removal, or their interaction (Table 1). Seed ingestion by badgers appeared to speed up seedling emergence during the first months after sowing (e.g., all seedlings that emerged during the first nine months $[n=8]$ came from badger-ingested seeds; Fisher's exact test, $P<0.0001)$. However, the percentage of emergences during the first year was very low
$(5.3 \%, n=265)$. Therefore, in contrast with our predictions, the Cox regression analysis did not reveal any overall effect of ingestion $\left(\chi^{2}=2.2, \mathrm{df}=1, P=\right.$ $0.138)$, removal $\left(\chi^{2}=1.6, \mathrm{df}=1, P=0.206\right)$, or their interaction $\left(\chi^{2}=2.0, \mathrm{df}=3, P=0.572\right)$ on the speed of seedling emergence through the entire study.

\section{Seedling survival}

A significant percentage of the overall emerged seedlings $(40.4 \%, n=265)$ survived to the end of the study. Most seedling mortality was due to desiccation, as denoted by symptoms such as browning of their leaves. Most seedlings $(82.3 \%, n=158)$ died during the first summer after emergence, which was related to the severe summer droughts. After controlling for the block effect, neither ingestion nor removal had significant effects as main factors on seedling survival $(P>0.126$; Table 1). Nevertheless, there was a significant interaction between ingestion and removal (Table 1), indicating that the effect on seedling survival of any one factor depended on the other factor levels (Fig. 1E). As predicted, tests of "slices" indicated that survival for seedlings emerged from badger-ingested seeds was 


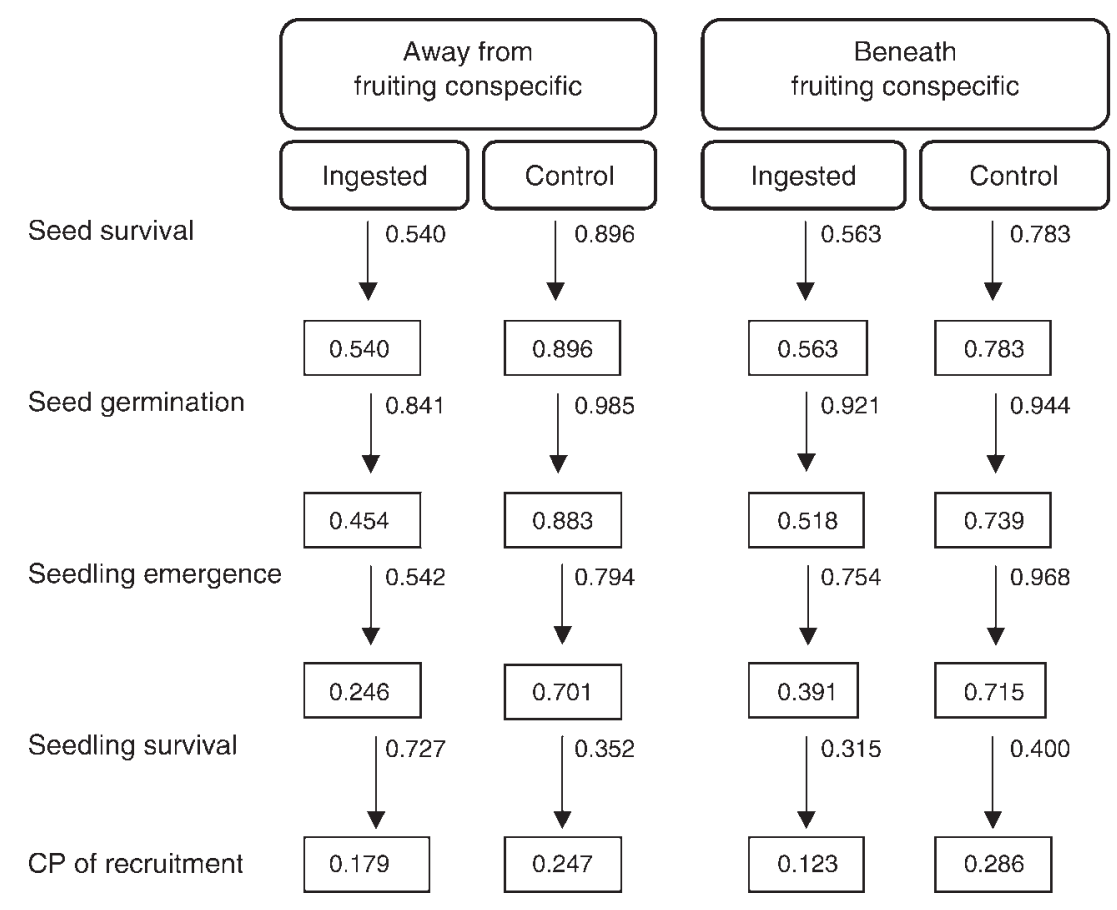

FIG. 2. Diagram of Chamaerops humilis propagule fate showing the proportion of seeds or seedlings moving from one stage to the next (i.e., transition probabilities, values next to the arrows) and the proportion of the initial propagules still alive at each stage (values inside the boxes). The overall cumulative probability (CP) of recruitment for each treatment combination is also shown.

higher away from than beneath fruiting conspecifics $\left(F_{1,247}=5.03, P=0.026\right)$; however, no differences in survival related to removal were found for control seeds $\left(F_{1,247}=1.07, P=0.301\right.$; Fig. $\left.1 \mathrm{E}\right)$. Thus, results on seedling survival provided only partial support for our initial expectations.

\section{Overall probability of recruitment}

Transition probabilities (TP) among all stages considered in this study and cumulative probabilities of recruitment are summarized in Fig. 2. In general, seed and seedling survival were the most critical bottlenecks in the $C$. humilis life cycle. Nevertheless, transition probabilities between stages were rather idiosyncratic among treatment combinations (Fig. 2). Specifically, for badger-ingested seeds, seed survival was a critical stage both beneath and away from reproductive conspecifics (TP indicated that, on average, only $55 \%$ of badgeringested seeds survived to reach this stage). In addition, seedling survival was key beneath fruiting conspecifics (Fig. 2). For control seeds, however, seedling survival was the most limiting stage (on average, barely $38 \%$ of emerged control seedlings survived to end of the study). Overall, the cumulative probabilities of recruitment (i.e., the product of all TPs) of a mature seed to reach the seedling stage and survive, at least over the first summer, was 1.38 and 2.33 times higher for control than for badger-ingested seeds beneath and away from conspecifics, respectively (Fig. 2). Finally, using available data from all 15 blocks, we calculated another estimate of overall probability of recruitment as the number of seedlings surviving at the end of the study over the number of sown seeds. Not surprisingly, a generalized linear mixed model using this estimate as response variable indicated that recruitment was less than half that for badger-ingested seeds as compared with control seeds $\left(F_{1,582}=21.58, P<0.0001\right)$. Neither removal $(P=$ $0.216)$ nor its interaction with ingestion $(P=0.906)$ had significant effects on this estimate of recruitment. Therefore, both recruitment estimates indicated that fruit ingestion by badgers inflicted considerable costs to C. humilis both at the individual propagule and the offspring levels.

\section{Discussion}

Our approach accounted for contrasting processes that took place at different stages of the $C$. humilis recruitment course (seed survival, germination, seedling survival, and establishment). This increased the comprehensiveness of the study and enhanced the likelihood of detecting the benefits and risks associated with the $C$. humilis-badger interaction. Indeed, in its interaction with badgers, $C$. humilis experienced seldom-accountedfor indirect fitness costs (Strauss and Irwin 2004), which added complexity to the nature of this fruit-frugivore interaction and supports the idea that the outcome of most species interactions is dependent on the community context in which they are embedded (Bronstein 1994, J. N. Thompson 2005). 


\section{The effects of seed ingestion and the removal from the maternal environment}

In agreement with previous comprehensive assessments (Cipollini and Levey 1997, Cippolini 2000), our results and field observations support the idea of the multifunctionality of $C$. humilis ripe pulp and also that pulp consumption by badgers had conflicting outcomes for the plant. First, when ripened, C. humilis pulp smells strongly of rancid butter and thus it might act as a foraging cue for nocturnal mammals such as badgers (who have poor eyesight and rely mostly on their sense of smell; Buesching and Macdonald 2001). Second, some results suggest an early inhibitory function of fruit pulp (all seedlings emerging during the first months after sowing came from badger-ingested seeds). Nevertheless, we did not find evidence of germination inhibition along the entire study, which could be related to a physicochemical and biological processing of $C$. humilis diaspores in the field, which could reproduce partly the effect of pulp consumption by badgers (Traveset et al. 2007, Fedriani and Delibes 2009a). Further experiments using hand-depulped fruits could help in identifying the relative contribution of pulp removal and seed scarification on patterns of seedling emergence. Third, seed predation by invertebrates was much lower for control than for badger-ingested seeds, suggesting that, as predicted, C. humilis fruit pulp defends seeds from predators. Our result supports Anstett's (1999) suggestion that, when damaged, a resin segregated by $C$. humilis fruit pulp appeared to prevent infestation by the curculionid Derelomus chamaeropsis (see also Langenhei 2003 for a review). Therefore, our study of a Mediterranean palm appears to corroborate those reported in tropical ecosystems, where higher predation rates by both bruchids (Silvius and Fragoso 2002, Fragoso et al. 2003) and some vertebrates (Filardi and Tewksbury 2005) take place on pulp-removed seeds. As suggested in those studies, it is likely that a combination of physical (fibers; Silvius and Fragoso 2002) and chemical (e.g., phenols, condensed tannins; Landau et al. 2002, Decandia et al. 2008) defenses allows $C$. humilis pulp to deter invertebrate seed predators while still being attractive to badgers. In other cases, the outcome of pulp removal is diminished by the additional fecal material embedding dispersed seeds, which can enhance seed survivorship (e.g., Fragoso et al. 2003); however, this possibility is unlikely in our study system because $C$. humilis endocarps are defecated with virtually no other fecal material embedding them. Finally, some other potential functions of $C$. humilis fruit pulp not accounted for in this study still exist, such as laxative effects (e.g., due to high sugar concentration) reducing gut transit times, which could decrease seed damage but, on the other hand, reduce dispersal distance (Cipollini 2000, Tewksbury et al. 2008). These potential functions would add more conditionality (sensu Bronstein 1994) to the outcome of the $C$. humilis-badger interaction and certainly deserve further research.
A substantial number of studies have found that departure from the maternal environment has positive effects on plant fitness (e.g., Augspurger 1984, Balcomb and Chapman 2003, Fragoso et al. 2003, Howe and Miriti 2004; but see Hyatt et al. 2003). Unexpectedly, however, we generally did not find any effect of removal from the maternal environment on any of the different components of $C$. humilis fitness, though seedling survival for badger-ingested seeds was higher away than beneath conspecifics. The general lack of distance effect could arise from the relatively small departure distance $(10 \mathrm{~m})$ tested in our field experiment, although it resembles the usual separation among badger latrines and $C$. humilis neighborhoods within the Mediterranean shrubland (a habitat in which palm density is relatively high; J. M. Fedriani and M. Delibes, unpublished data). For example, Fragoso et al. (2003) found that tapirs enhance survival of Maximiliana maripa palm seeds by delivering them long distances away from adult palm aggregations, since rates of bruchid predation were much higher near $M$. maripa palms. Interestingly, however, we found an effect of removal from fruiting conspecifics using the same departure distance $(10 \mathrm{~m})$ in an earlier study on other mammal-dispersed Mediterranean species (i.e., Pyrus bourgaeana; Fedriani and Delibes 2009b). Contrasting results between this study and that earlier field experiment can be related to particular foraging determinants of seed predators (bruchids and rodents, respectively) and spatial and/or temporal variations of factors such as the availability of alternative foods (Fedriani and Manzaneda 2005, Klinger and Rejmánek 2009). Why other factors such as fungal pathogens, chemical allelopathy, and mechanical inhibition generally associated with fruiting plants (Janzen 1970, Fenner and Thompson 2005) did not lead to lower reproductive performance remains unsolved. Nonetheless, we frequently have observed in Doñana $C$. humilis seedlings establishing beneath fruiting palms, likely due to dispersal limitation (e.g., Chapman and Chapman 1995, Cordeiro and Howe 2003), which suggests relatively suitable biotic and abiotic conditions beneath conspecifics.

\section{Badger dispersal effectiveness and overall probability of recruitment}

Our experimental results suggest a relatively low effectiveness of badger seed dispersal. In particular, predation by bruchids on badger-ingested seeds was much higher than on non-ingested seeds, and such substantial cost was not overridden by benefits experienced during other ontogenic plant stages. However, the reported high cost of dispersal in terms of depredated seeds is similar to or even lower than that found in other plant-disperser systems (Iida 2004, 2006, Nogales et al. 2005, Gómez et al. 2007). Even though the cumulative probabilities of recruitment for badger-ingested seeds were always lower than for control seeds (Fig. 2), a nonnegligible fraction of badger-ingested seeds (12- 
$18 \%$ ) led to established seedlings. Such value of recruitment is much higher than those reported for other fleshy-fruited species both in temperate (Rey and Alcántara 2000, Traveset et al. 2003) and tropical ecosystems (Balcomb and Chapman 2003), indicating that, though endozoochory imposed a substantial cost to $C$. humilis, badgers acted as reliable dispersers.

A critical point in assessing the nature of species interactions relates to benefits or costs unaccounted for (Bronstein 2001). For example, though in our study system pre-dispersal seed predation by vertebrates mostly occurs on developing seeds, badgers eventually could benefit $C$. humilis by allowing some mature seeds to escape from infrequent vertebrate predation events. Fecal material accompanying dispersed seeds can act as fertilizer, enhancing seedling growth and survival (Dinerstein and Wemmer 1988, Traveset et al. 2001a). Nonetheless, this rarely supported mechanism (Traveset et al. 2007) seems particularly unlikely in our study system because: (1) C. humilis endocarps are defecated by badgers nearly without other fecal material attached, (2) this palm has a well-known ability to thrive on poornutrient soils (Herrera 1989, Simón et al. 2010), and (3) seedling mortality in Doñana is linked mostly to summer droughts (J. M. Fedriani and M. Delibes, unpublished data). However, and more importantly, badgers are highly mobile (Fedriani et al. 1999, Revilla and Palomares 2002) and thus they likely act as longdistance seed dispersers (Nathan and Muller-Landau 2000). In Doñana, badgers deliver some $C$. humilis seeds to habitats where $C$. humilis are absent or occur at low densities (e.g., the "dehesa"; Fedriani et al. 1999, 2010); thus, they likely enable the colonization of new areas. In addition to the benefits at the individual (higher survival, lower intraspecific competition, etc.) and population (colonization of vacant habitats) levels, long-distance dispersal could be a paramount process at the metapopulation level, particularly in heterogeneous and fragmented landscapes (Levin et al. 2003, Spiegel and Nathan 2007, Nathan et al. 2008). Given the severe fragmentation of Doñana habitats, where local populations and suitable vacant patches are isolated from one another by both anthropogenic and natural barriers (Fedriani et al. 2010), badgers likely facilitate inter-patch connectivity and gene flow (Nathan 2006). Consequently, the short-term costs of seed dispersal by badgers at the individual level should be balanced against the long-term benefits at the metapopulation level (Levin et al. 2003, Spiegel and Nathan 2007, Nathan et al. 2008).

Although our results highlight the costs of seed dispersal, whether or not such costs exceeded the benefits is a complex and context-dependent issue (e.g., Holland et al. 2002). For example, the long-standing benefits in terms of population survival and spread are difficult to measure (especially for long-lived species [e.g., C. humilis] and highly mobile vectors [e.g., badger]) and, therefore, unknown to our and most seed-disperser systems (Schupp et al. 2010). The magnitude of both benefits and costs are contingent and highly dependent on the ecological context (e.g., density of seed predators, presence of alternative dispersers, etc.; Holland et al. 2002). In our study site, $C$. humilis has virtually no alternative disperser other than the badger, since most potential dispersers have gone extinct due to human persecution (e.g., wolves [Canis lupus] and bears [Ursus arctos]) or are at present very scarce (e.g., the red fox; Fedriani et al. 2010). Thus, though seed ingestion and dispersal by badgers impose a sizeable short-term fitness cost to $C$. humilis, badgers could provide a major service to this palm by dispersing it in a highly fragmented landscape, where most alternative dispersers are extinct. Badgers can be categorized as engaging in "dangerous liaisons" with C. humilis, though they appear gentle when compared with apparently unconditional enemies, such as rabbit and deer, which acted as predators of undeveloped seeds. Therefore, badgers and other opportunistic consumers (e.g., red foxes, where abundant) are likely playing a part in the recently observed (Médail and Quézel 1996) and predicted (Harrison et al. 2006) northward expansion of $C$. humilis range in the Mediterranean basin.

To conclude, mutualisms are characterized by both benefits and costs. A thorough consideration of these conflicting forces is mandatory to advance our understanding of their ecological and evolutionary outcomes in both natural and humanized landscapes (Bronstein et al. 2004). Costs and benefits also are pervasive among seed-disperser systems, including endozoochores, epizoochores, and both vertebrate- and invertebratedispersed plants (Herrera and Pellmyr 2002, Bronstein et al. 2007). Our study is novel in exemplifying that the outcomes of plant-disperser interactions should be appraised concurrently with the direct and indirect effects exerted by other species interacting with plants at different stages of their life cycles and recruitment processes.

\section{ACKNOWLEDGMENTS}

We are indebted to Gemma Calvo, Mónica Váz, and innumerable volunteers for their enthusiastic field and laboratory assistance. We thank Victor Parra-Tabla, Montse Vilà, and three anonymous reviewers for thoughtful comments on earlier versions of the manuscript. The Spanish Ministerio de Medio Ambiente (National Park Service, grants 15/2003 and 070/2009) and Ministerio de Educación y Ciencia (CGL2007-63488/BOS and CGL2010-21926/BOS) supported this study.

\section{Literature Cited}

Anstett, M. C. 1999. An experimental study of the interaction between the dwarf palm (Chamaerops humilis) and its floral visitor Derelomus chamaeropsis throughout the life cycle of the weevil. Acta Oecologica 20:551-558.

Augspurger, C. K. 1984. Seedling survival of tropical tree species: interactions of dispersal distance, light-gaps, and pathogens. Ecology 65:1705-1712.

Balcomb, S. R., and C. A. Chapman. 2003. Bridging the gap: influence of seed deposition on seedling recruitment in a primate-tree interaction. Ecological Monographs 73:625642 . 
Barbosa, P., and I. Castellanos. 2005. The ecology of predatorprey interactions. Oxford University Press, Oxford, UK.

Barillas-Mury, C., and S. Kumar. 2005. Plasmodium-mosquito interactions: a tale of dangerous liaisons. Cell Microbiology 7:1539-1545.

Booth, R., and Y. Ghend. 1993. Seed viability and germination. Pages 10-13 in G. A. F. Hendry and J. P. Grime, editors. Methods in comparative plant ecology: a laboratory manual. Chapman and Hall, London, UK.

Bronstein, J. L. 1994. Conditional outcomes of mutualistic interactions. Trends in Ecology and Evolution 9:214-217.

Bronstein, J. L. 2001. The costs of mutualism. American Zoologist 41:127-141.

Bronstein, J. L., R. Alarcon, and M. Geber. 2006. The evolution of plant-insect mutualisms. New Phytologist 172: $412-428$.

Bronstein, J. L., U. Dieckmann, and R. Ferrière. 2004 Coevolutionary dynamics and the conservation of mutualisms. Pages 305-326 in R. Ferrière, U. Dieckmann, and D. Couvet, editors. Evolutionary conservation biology. Cambridge University Press, Cambridge, UK.

Bronstein, J. L., I. Izhaki, R. Nathan, J. J. Tewksbury, O. Speigel, and A. Lotan. 2007. Fleshy-fruited plants and frugivores in desert ecosystems. Pages 148-177 in A. J. Dennis, E. W. Schupp, R. J. Green, and D. W. Westcott, editors. Seed dispersal: theory and its application in a changing world. Cambridge University Press, Cambridge, UK.

Buesching, C. D., and D. W. Macdonald. 2001. Scent-marking behaviour of the European badger (Meles meles): resource defense or individual advertisement? Pages 321-327 in A. Marchlewska-Koj, J. L. Lepri, and D. Müller-Schwarze, editors. Chemical signals in vertebrates 9. Kluwer Academic/ Plenum, New York, New York, USA.

Cazetta, E., H. M. Schaefer, and M. Galetti. 2008: Does attraction to frugivores or defense against pathogens shape fruit pulp composition? Oecologia 155:277-286.

Chapman, C. A., and L. J. Chapman. 1995. Survival without dispersers: seedling recruitment under parents. Conservation Biology 9:675-678.

Cipollini, M. L. 2000. Secondary compounds in fleshy fruits: evidence for adaptive functions. Revista Chilena de Historia Natural 73:243-252.

Cipollini, M. L., and D. J. Levey. 1997. Secondary metabolites of fleshy vertebrate-dispersed fruits: adaptive hypotheses and implications for seed dispersal. American Naturalist 150: 346-372.

Cordeiro, N. J., and H. F. Howe. 2003. Forest fragmentation severs mutualism between seed dispersers and an endemic African tree. Proceedings of the National Academy of Sciences USA 100:14052-14056.

Decandia, M., A. Cabiddu, M. Sitzia, and G. Molle. 2008. Polyethylene glycol influences feeding behaviour of dairy goats browsing on bushland with different herbage cover. Livestock Science 116:183-190.

Dinerstein, E., and C. M. Wemmer. 1988. Fruits Rhinoceros eat: dispersal of Trewia nudiflora (Euphorbiaceae) in lowland Nepal. Ecology 69:1768-1774.

Ellstrand, N. C. 2003. Dangerous liaisons? When cultivated plants mate with their wild relatives. Johns Hopkins University Press, Baltimore, Maryland, USA.

Fedriani, J. M., and M. Delibes. 2009a. Functional diversity in fruit-frugivore interactions: a field experiment with Mediterranean mammals. Ecography 32:983-992.

Fedriani, J. M., and M. Delibes. 2009b. Seed dispersal in the Iberian pear Pyrus bourgaeana: a role for infrequent mutualists. Ecoscience 16:211-221.

Fedriani, J. M., and A. J. Manzaneda. 2005. Pre- and postdispersal seed predation by rodents: balance of food and safety. Behavioral Ecology 16:1018-1024.
Fedriani, J. M., F. Palomares, and M. Delibes. 1999. Niche relations among three sympatric mediterranean carnivores. Oecologia 121:138-148.

Fedriani, J. M., T. Wiegand, and M. Delibes. 2010. Spatial patterns of adult trees and the mammal-generated seed rain in the Iberian pear. Ecography 33:545-555.

Fenner, M., and K. Thompson. 2005. The ecology of seeds. Cambridge University Press, Cambridge, UK.

Filardi, C. E., and J. Tewksbury. 2005. Ground-foraging palm cockatoos (Probosciger aterrimus) in lowland New Guinea: Fruit flesh as a directed deterrent to seed predation? Journal of Tropical Ecology 21:355-361.

Fragoso, J. M. V., K. M. Silvius, and J. A. Correa. 2003. Longdistance seed dispersal by tapirs increases seed survival and aggregates tropical trees. Ecology 84:1998-2006.

Gómez, J. M., C. Puerta-Piñero, and E. W. Schupp. 2007. Effectiveness of rodents as local seed dispersers of Holm oaks. Oecologia 155:529-537.

Gómez, J. M., and R. Zamora. 2005. Ecological factors promoting the evolution of generalization in pollination systems. Pages 145-166 in N. Waser and J. Ollerton, editors. Generalization and specialization in plant pollinator systems. University of Chicago Press, Chicago, Illinois, USA.

González-Benito, M. E., M. Huertas-Micó, and F. PérezGarcía. 2006. Seed germination and storage of Chamaerops humilis (dwarf fan palm). Seed Science and Technology 34: 143-150.

Harrison, P. A., P. M. Berry, N. Butt, and M. New. 2006. Modeling climate change impacts on species distributions at the European scale: implications for conservation policy. Environmental Science Policy 9:116-128.

Hasnaoui, O., M. Bouazza, and M. Thinon. 2009. Kinetical germination study of the Chamaerops humilis L. var. argentea Andre (Arecaceae). Environmental Research Journal 3:7680 .

Herrera, C. M. 2009. Multiplicity in unity: plant subindividual variation and interactions with animals. University of Chicago Press, Chicago, Illinois, USA.

Herrera, C. M., and O. Pellmyr. 2002. Plant-animal interactions: an evolutionary perspective. Blackwell Science, Oxford, UK.

Herrera, J. 1989. On the reproductive biology of the dwarf palm, Chamaerops humilis, in southern Spain. Principes 33: $27-32$.

Holland, J. N., D. L. DeAngelis, and J. L. Bronstein. 2002. Population dynamics and mutualism: functional responses of benefits and costs. American Naturalist 159:231-244.

Howe, H. F., and M. N. Miriti. 2004. When seed dispersal matters. BioScience 54:651-660.

Hyatt, L. A., M. S. Rosenberg, T. G. Howard, G. Bole, W. Fang, J. Anastasia, and K. Brown. 2003. The distance dependence prediction of the Janzen-Connell hypothesis: a meta-analysis. Oikos 103:590-602.

Iida, S. 2004. Indirect negative influence of dwarf bamboo on survival of Quercus acorn by hoarding behavior of wood mice. Forest Ecolology Management 202:257-263.

Iida, S. 2006. Dispersal patterns of Quercus serrata acorns by wood mice in and around canopy gaps in a temperate forest. Forest Ecology Management 227:71-78.

Janzen, D. H. 1970. Herbivores and the number of tree species in tropical forests. American Naturalist 104:501-528.

Klinger, R., and M. Rejmánek. 2009. The numerical and functional responses of a granivorous rodent and the fate of Neotropical tree seeds. Ecology 90:1549-1563.

Kruuk, H. 1989. The social badger: ecology and behaviour of a group-living carnivore (Meles meles). Oxford University Press, Oxford, UK.

Landau, S., S. Friedman, L. Devash, and S. J. Mabjeesh. 2002. Polyethylene glycol, determined by near-infrared reflectance 
spectroscopy, as a marker of fecal output in goats. Journal of Agricultural and Food Chemistry 50:1374-1378.

Langenhei, J. H. 2003. Plant resins: chemistry, evolution, ecology and ethnobotany. Timber Press, Portland, Oregon, USA.

Levin, S. A., H. C. Muller-Landau, R. Nathan, and J. Chave. 2003. The ecology and evolution of seed dispersal: a theoretical perspective. Annual Review of Ecology and Systematics 34:575-604.

Médail, F., and P. Quézel. 1996. Climatic and phytoecological significance of the rediscovery in Mediterranean France of Chamaerops humilis L. (Palmae). Comptes Rendus de l'Academie des Sciences Serie III Sciences de la Vie 319: 139-145.

Nathan, R. 2006. Long-distance dispersal of plants. Science 313:786-788.

Nathan, R., and H. C. Muller-Landau. 2000. Spatial patterns of seed dispersal, their determinants and consequences for recruitment. Trends in Ecology and Evolution 15:278-284.

Nathan, R., F. M. Schurr, O. Spiegel, O. Steinitz, A. Trakhtenbrot, and A. Tsoar. 2008. Mechanisms of longdistance seed dispersal. Trends in Ecology and Evolution 23: 638-647.

Nogales, M., C. Nieves, J. C. Illera, D. P. Padilla, and A. Traveset. 2005. Effect of native and alien vertebrate frugivores on seed viability and germination patterns of Rubia fruticosa (Rubiaceae) in the eastern Canary Islands. Functional Ecology 19:429-436.

Revilla, E., and F. Palomares. 2002. Spatial organization, group living and ecological correlates in low-density populations of Eurasian badgers, Meles meles. Journal of Animal Ecology 71:497-512.

Rey, P. J., and J. M. Alcántara. 2000. Recruitment dynamics of a fleshy-fruited plant (Olea europaea): connecting patterns of seed dispersal to seedling establishment. Journal of Ecology 88:622-633.

Robertson, A. W., A. Trass, J. J. Ladley, and D. Kelly. 2006. Assessing the benefits of frugivory for seed germination: the importance of deinhibition effect. Functional Ecolology 20: $58-66$.

Rodríguez, J., N. Riera, and A. Traveset. 2005. Effect of seed passage through birds and lizards on emergence rate of Mediterranean species: differences between natural and controlled conditions. Functional Ecology 19:429-436.

Santamaría, L., I. Charalambidou, J. Figuerola, and A. J. Green. 2002. Effect of passage through duck gut on germination of fennel pondweed seeds. Archiv für Hydrobiologie 156:11-22.

SAS Institute. 2005. SAS/STAT software: changes and enhancements through release 6.12. SAS Institute, Cary, North Carolina, USA.

Schupp, E. W. 2007. The suitability of a site for seed dispersal is context-dependent. Pages 445-462 in A. J. Dennis, E. W. Schupp, R. J. Green, and D. W. Westcott, editors. Seed dispersal: theory and its application in a changing world. CAB International, Wallingford, UK.
Schupp, E. W., P. Jordano, and J. M. Gómez. 2010. Seed dispersal effectiveness revisited: a conceptual review. New Phytologist. [doi: 10.1111/j.1469-8137.2010.03402.x]

Silvius, K. M., and J. M. V. Fragoso. 2002. Pulp handling by vertebrate seed dispersers increases palm seed predation by bruchid beetles in the northern Amazon. Journal of Ecology 90:1024-1032.

Simón, M. D., M. Nieves-Cordones, and M. Nieves. 2010. Differences in growth and ornamental parameters between young Chamaerops humilis L. and Washingtonia robusta $\mathrm{H}$. Wendl palm trees in response to salinity. Journal of Horticulture Science and Biotechnology 85:7-11.

Spiegel, O., and R. Nathan. 2007. Incorporating dispersal distance into the disperser effectiveness framework: frugivorous birds provide complementary dispersal to plants in patchy environments. Ecology Letters 10:718-728.

Strauss, S. Y., and R. E. Irwin. 2004. Ecological and evolutionary consequences of multispecies plant-animal interactions. Annual Review of Ecology, Evolution and Systematics 35:435-466.

Tewksbury, J. J., D. J. Levey, M. Huizinga, and A. Traveset. 2008. Ecology of a spice: capsaicin in wild chilies mediates seed retention, dispersal, and germination. Ecology 89:107117.

Therneau, T. M., and P. M. Grambsch. 2000. Modeling survival data: extending the Cox model. Springer, New York, New York, USA.

Thompson, J. D. 2005. Plant evolution in the Mediterranean. Oxford University Press, Oxford, UK.

Thompson, J. N. 2005. The geographic mosaic of coevolution. University of Chicago Press, Chicago, Illinois, USA.

Traveset, A., T. Bermejo, and M. F. Willson. 2001a. Effect of manure composition on seedling emergence and growth of two common shrub species of Southeast Alaska. Plant Ecology 155:29-34.

Traveset, A., J. Gulías, N. Riera, and M. Mus. 2003. Transition probabilities from pollination to establishment in a rare dioecious shrub species (Rhamnus ludovici-salvatoris) in two types of habitats. Journal of Ecology 91:427-437.

Traveset, A., N. Reira, and R. E. Mas. 2001b. Passage through bird guts causes interspecific differences in seed germination characteristics. Functional Ecology 15:669-675.

Traveset, A., A. Robertson, and J. Rodríguez-Pérez. 2007. A review of the role of endozoochory on seed germination. Pages 79-103 in A. J. Dennis, E. W. Schupp, R. J. Green, and D. W. Westcott, editors. Seed dispersal: theory and its application in a changing world. CAB International, Wallingford, UK.

van Baalen, M., and V. A. A. Jansen. 2001. Dangerous liaisons: the ecology of private interest and common good. Oikos 95: 211-224.

Verdú, M., and A. Traveset. 2005. Early emergence enhances plant fitness: a phylogenetically controlled meta-analysis. Ecology 86:1385-1394.

Vilà, M., I. Bartomeus, I. Gimeno, A. Traveset, and E. Moragues. 2006. Demography of the invasive geophyte Oxalis pes-caprae across a Mediterranean island. Annals of Botany 97:1055-1062.

\section{APPENDIX}

Photographs of Chamaerops humilis (Ecological Archives E092-027-A1). 